\title{
ALFREDA MURCK
}

\section{SU SHI AND ZHAO LINGRANG}

\author{
Brush Ideas of Wang Wei
}

ABSTRACT

The poet and painter Wang Wei (699-759) of the Tang dynasty (618-907) "had poetry in his painting and painting in his poetry." With that claim, Su Shi (1037-1101) linked painting with a prestigious literary genre. Although no one believed that painting held a status equal to poetry, eleventh-century appropriations of literary forms and allusions into painting were an important development in the history of Chinese culture. The literary turn elevated painting to an elite art.

Connoisseurs of the eleventh and later centuries saw connections to Wang Wei in the paintings of Zhao Lingrang (active 1070-after 1100). Su Shi and Huang Tingjian (1045-1105) encouraged Zhao's efforts. The connoisseur Dong Qichang (1555-1636) of the Ming dynasty (1368-1644), after carefully studying Summer Mist along the Lakeshore (Huzhuang qingxia tu 湖莊清夏圖), wrote in a colophon on the handscroll (now in the Museum of Fine Arts, Boston) that Zhao's composition thoroughly followed the brush ideas (bi yi 筆意) of Wang Wei.

This essay argues that what Su Shi encouraged, what Zhao Lingrang created in Summer Mist, and what Dong Qichang observed was a relationship that transcended mere imitation of brushwork. Zhao's connection to Wang Wei was not stylistic, but rather was a matter of approach: Zhao was working like a literatus, thinking in poetic structures, and expressing his thoughts by painting literary metaphors. Poetic structure will be analyzed as well as three literary tropes: trees, gurgling stream, and the configuration of eight rocks.
The Tang-dynasty (618-907) literatus Wang Wei 王維 (699-759) "had poetry in his painting and painting in his poetry."1 With that observation, Su Shi 蘇軾 (1037-1101), the prominent writer, artist, and statesman, linked painting to a revered literary genre while asserting the permeability of the two arts: artists could paint poetic tropes just as poets could use words to conjure visual scenes. Su Shi's elevation of painting to an elite art encouraged educated men to adopt the authorial voice of writers as they sketched pictures with their calligraphy brushes. Eleventh-century experiments in adapting literary imagery and forms for painting were influential in the development of Chinese elite culture. In this process, the imperial clansman Zhao Lingrang 趙令讓 (active 1070-after 1100) played a significant role. ${ }^{2}$

Zhao Lingrang's small handscroll Summer Mist along the Lakeshore (Huzhuang qingxia tu 湖莊清 夏圖) is widely regarded as his finest surviving work (figs. 1a, 1b). When the cultural arbiter Dong
QUICK CITATION

Murck, Alfreda. "Su Shi and Zhao Lingrang: Brush Ideas of Wang Wei." Ars Orientalis 49 (2019): 3-21. 
FIGURE 1A. Zhao Lingrang (active 1070-after 1100), Summer Mist along the Lakeshore (detail, right half), 1100.

Handscroll, ink and light color on silk; image: $19.1 \times 161.3 \mathrm{~cm}$. Museum of Fine Arts, Boston, Keith McLeod Fund, 57.724

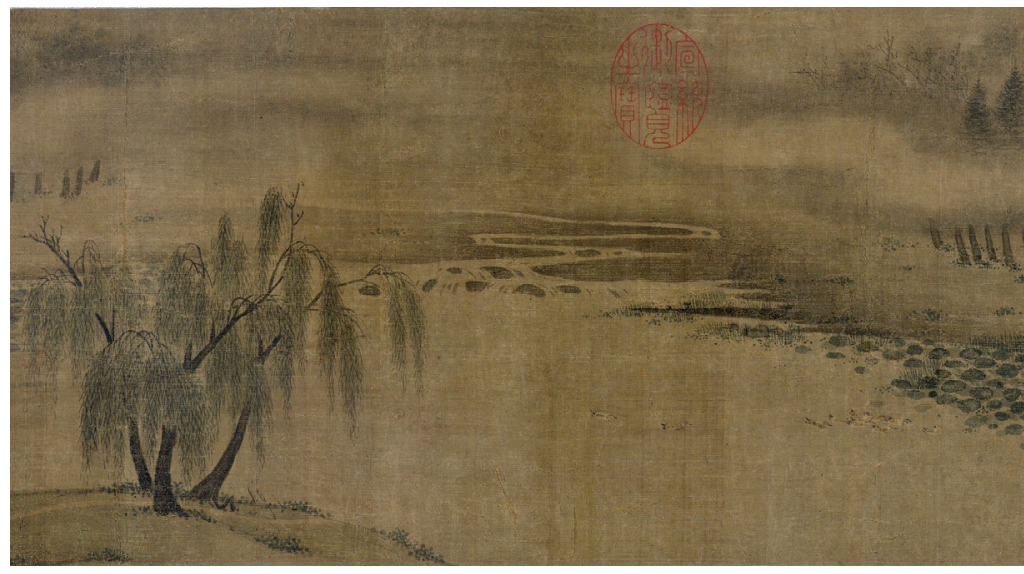

FIGURE 1B. Zhao Lingrang, Summer Mist along the Lakeshore, detail, left half

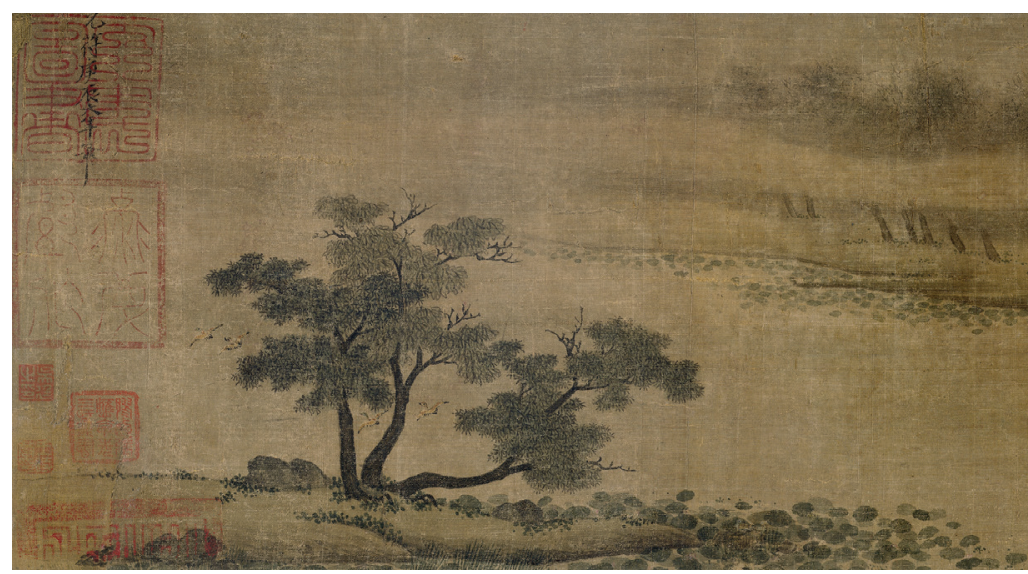

Qichang 董其昌 (1555-1636) acquired the painting, he studied it for some days and declared that Zhao Lingrang had thoroughly followed Wang Wei's brush ideas. ${ }^{3}$ Dong did not elaborate, but it is likely that he meant that Zhao had followed more than the elegance and understatement for which Wang Wei was known. Inspired by Dong Qichang's comment, this article makes two distinct but related arguments. The first suggests that Zhao Lingrang structured Summer Mist in imitation of a poetic form. The second is that Zhao was expressing his thoughts through established poetic tropes, and for this approach he owed as much to Su Shi as to Wang Wei.

Initially Wang Wei's paintings took third place behind his brilliant poetry and fine musicianship. That he enjoyed painting is not in doubt: he once observed that, in a former life, he must have been a painter. ${ }^{4}$ The Tang-dynasty critic Zhang Yanyuan 張彥遠 (ca. 815-after 875) credited Wang with bridging ancient and modern styles but found him lacking on technical grounds. Robert Harrist has described his eleventh-century apotheosis from a respected minor painter "to a position of supreme importance in the history of Chinese painting," a transformation in which Su Shi's voice was critical. Comparing paintings by the professional master Wu Daozi 吳道子 (680-ca. 760) and the literatus Wang Wei, Su praised Wang Wei as an immortal crane who had left his worldly cage, and whose paintings rendered Su speechless. ${ }^{5}$

Regrettably no reliable Wang Wei paintings survive today, but during Zhao's lifetime, dozens of works attributed to Wang circulated, generally admired for their quiet elegance. The late Northern Song (960-1127) imperial painting catalogue Xuanhe huapu 宣和畫譜 (Xuanhe 
In a thorough review of Zhao Lingrang's extant paintings and imitators, Robert Maeda has recognized Summer Mist along the Lakeshore as an important link between the monumental landscapes of the Northern Song and the lyrical, small-scale scenes of the Southern Song (1127-1279). ${ }^{11}$

\section{Historical Background}

Growing up in Kaifeng 開封 in an imperial-clan palace, Zhao Lingrang was educated in the classics, history, philosophy, and poetry. He would have memorized poetry, internalizing the patterns of regulated verses in four-line quatrains and eight-line octaves. It was said that, as a child, he recited the poems of Du Fu 杜甫 (712-770). ${ }^{12}$ This would have given Zhao common ground with Su Shi and the official and poet Huang Tingjian 黃庭堅 (1045-1105), who admired Du Fu for his unique voice and compassionate social critiques.

In capital society, Zhao surely knew the accomplished amateur painter and poet Wang Shen 王詵 (ca. 1048-ca. 1104), a military man who had married the younger sister of Emperor Shenzong 神宗 (r. 1067-85). Both Zhao and Wang tutored little Zhao Ji 趙佶 (1082-1135), the prince who precipitously was made emperor in $1100 .{ }^{13}$ Zhao Lingrang and Wang Shen both had friends among the antireformists, many of whom wrote poems for their paintings. Those included Su Shi, Huang Tingjian, Chao Buzhi 昆補之 (1053-1110), Chao Yuezhi 昆說之 (1059-1129), Zhang Lei 張未 (1054-1114), Zhang Shunmin 張舜民 (ca. 1034-ca. 1110), and the monk Dao Qian 道潛 (style name Canliao 參零, 1043-ca. 1116).$^{14}$ Huang Tingjian personally encouraged Zhao in his painting, noting that he had learned from Su Shi and therefore was able to paint hills and thick groves that could convey exceptional meanings. ${ }^{15}$ The painter and poet Mi Fu 米䒾 (1051-1107) saw an affiliation between Wang Shen, Zhao Lingrang, and Su Shi; in his Painting History (Hua shi 畫史), Mi grouped the three together. Dong Qichang wrote that Zhao Lingrang and Wang Shen shared an approach to painting that was different from paintings of the court academy. ${ }^{16}$

Zhao Lingrang signed Summer Mist with a date equivalent to 1100, a momentous year in Northern Song governance. In the first month of that year, Emperor Zhezong 哲宗 (r. 1086-1100) unexpectedly died at the age of twenty-four without an heir. On the same day that Zhezong's death was announced, Zhao Lingrang's former pupil, Zhao Ji, was chosen as the most suitable of Shenzong's surviving sons and was enthroned as Huizong 徽宗 (r. 1100-1125). ${ }^{17}$ The next day, the new emperor declared a general amnesty.

For three decades prior to 1100, the hot-button controversy at the Northern Song court was the New Policies (Xinfa 新法) formulated by Wang Anshi 王安石 (1021-1086) for Emperor Shenzong. An antireform coalition, led by Sima Guang 司馬光 (1019-1086), argued that the New Policies were burdening the people with heavy taxes. ${ }^{18}$ The fractious political atmosphere forced officials to take sides. Those who supported the emperor's programs rose in the bureaucracy; those who opposed the policies were summarily cashiered, posted to the provinces, or exiled outright.

Zhao Lingrang befriended officials in the antireform coalition, which was not a problem when they were in the ascendency, as they were in the late 1080s. At that time, following Emperor Shenzong's death, the Empress Dowager Gao 高太皇太后 (1032-1093), who was sympathetic to the antireform officials, was serving as regent to the child emperor Zhezong. This was the Yuanyou 元祐 era (1086-93), which forever became associated with the celebrated officials that the empress dowager brought back into government from political exile: the elder statesman Sima Guang, the audacious Su Shi, and the brilliant wordsmith Huang Tingjian. Sima Guang was the political leader of the antireform group, while Su Shi was the luminous 
star at the center of an intellectual coterie that occasionally included Zhao Lingrang. Glorified in history despite acrimonious infighting that paralyzed government, the Yuanyou era and its reversal of reform policies did not last long. When Empress Dowager Gao died in 1093, Zhezong was old enough to rule. He reinstated his father's reform policies and rid the court of antireformists. Off went Su Shi, Huang Tingjian, Zhang Lei, and others into ever more remote exiles.

After seven years of restoration of the New Policies, Zhezong died in 1100, the year inscribed by Zhao on his painting. Because the new emperor declared an amnesty, Zhao Lingrang's friends were allowed to return to the capital. Su Shi was summoned from distant Hainan Island 海南島. Huang Tingjian was returning from southern Sichuan 四川. Was a restoration of Yuanyou culture imminent? What should one paint? If Zhao Lingrang wanted to comment on these momentous events, his challenge was to show grief and respect for the recently deceased emperor while anticipating the promise of this new moment. The Summer Mist landscape may have been his solution, for it skillfully incorporates metaphors of sadness and hope, of obscured and clear vision.

\section{The Compositional Structure of Summer Mist}

Our understanding of the eleventh-century perception of Wang Wei's style is imperfect, but by examining the composition of Summer Mist, we can infer that Zhao Lingrang was using a poetic structure. The number and placement of motifs suggest a quartile composition inspired by a quatrain.

Zhao Lingrang was not the first to borrow a literary form for painting. At least a quartercentury earlier, in the mid-1070s, the government official Song Di 宋迪 (ca. 1015-ca. 1080) designed the Eight Views of Xiao Xiang (Xiaoxiang bajing 瀟湘八景) following the form of an eightline regulated verse (lü shi 律詩). The appropriation of the regulated-verse form is evident in the eight titles of the paintings. And although Song Di's paintings do not survive, a set of Eight Views of Xiao Xiang paintings datable to the Southern Song visually manifests some key structures of regulated verse. Parallelism is particularly evident in the contrast of high and low: the high point of view that the painter adopted for Mountain Market, Clearing Mist (Shanshi qinglan 山市晴嵐) contrasts with the water-level perspective that he used in the following scene, River and Sky, Evening Snow (Viangtian muxue 江天暮雪). In addition, the two horizontal scenes, when viewed as a pair, both have mountain masses on the outer edges and water dominating the middle. Following a regulated-verse convention, for the next pair of paintings the artist did just the opposite: a modest mountain dominates the left side of Autumn Moon over Lake Dongting (Dongting qiuyue 洞庭秋月), the edge of which neatly matches up with a rocky hillside on the right side of Night Rain over Xiao Xiang (Xiaoxiang yeyu 瀟湘夜雨), while water occupies the outer edges of the two paintings. ${ }^{19}$ Other motifs reinforce the suggestion of visual parallelism: for example, the railings at the beginning and end of Clearing Mist and Evening Snow and, further, the tumbling mountain stream that flows from Autumn Moon into the adjacent Night Rain.

Although Zhao Lingrang's poetic structure is less obvious than that seen in the twelfthcentury Eight Views of Xiao Xiang, the four-part structure can be made out. Four groups of three trees punctuate the foreground in a sequence resembling the complementary juxtapositions in poetic couplets: leafy trees/willows, willows/leafy trees. ${ }^{20}$ The willows at the opening lean to the left and the leafy tree in the last group leans to the right, suggesting a calculated contrast. Abundant birds on the banks, in the trees, and on the water contribute to a peaceful scene and create further antithetical juxtapositions. For example, four birds perching on bare branches in the first cluster of trees are complemented at the left end of the composition by four ducks tak-

ing flight (figs. 2a, 2b). The four small birds are up high and still; the four large ducks are low and 
in motion. A plausible numerical contrast is evoked through two oriole-like birds with a dozen or so ducks (figs. 3a, 3b). The two birds rest on branches in the first cluster of willows; the pair is high, still, and dry, with dark feathers. ${ }^{21}$ By comparison, the waterfowl paddling on the surface

FIGURE 2A. Zhao Lingrang, Summer Mist along the Lakeshore, detail of four birds sitting in tree top

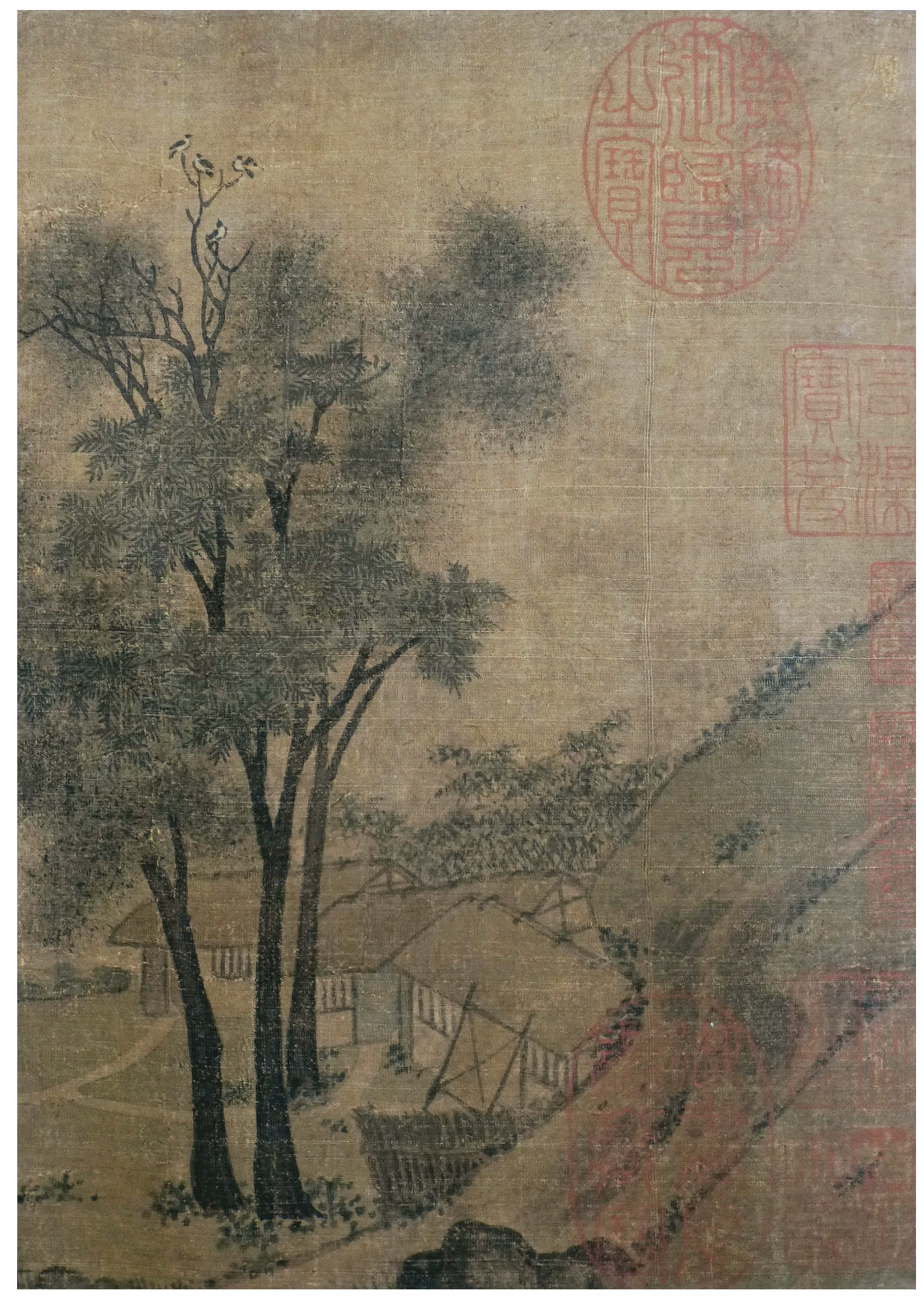




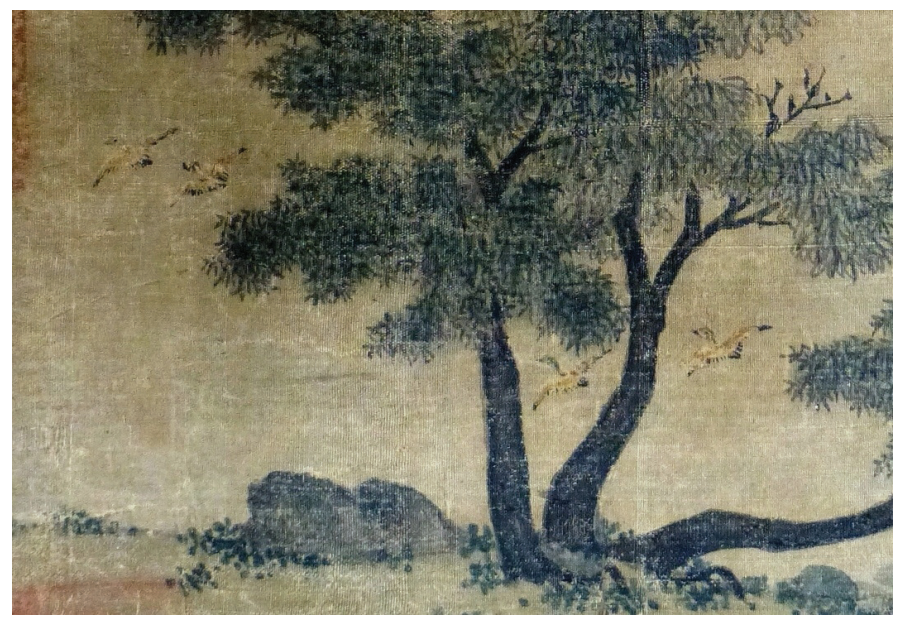

FIGURE 2B. Zhao Lingrang, Summer Mist along the Lakeshore, detail of four ducks flying at water level

of the water are numerous, low, in motion, and wet, with colorful feathers. Poets were expected to compose parallel couplets with these kinds of oppositions, similarities, and contrasts.

Two bridges form another complementary pair. Near the beginning of the composition a bridge with an earthen top connects foreground to middle ground (fig. $4 \mathrm{a}$ ), and just past the middle of the composition a wood-plank bridge zigzags across the water (fig. 4b). The two bridges contrast in both design and material, one made with earth ( $t u$ 土), the other with wood ( $m u$ 木).

Three small cottages at the opening of the scroll on the near bank are complemented by four cottages across the water toward the middle of the painting, their importance signaled by trees that are not shrouded in mist but stand like sentinels. Human habitation is evident from paths that run to and from the cottages, but, despite the well-trod paths, no people are seen. ${ }^{22}$

An effective compositional unifier is Zhao's signature use of mist, which in Summer Mist weaves in a binary alternation of near and far. ${ }^{23}$ At the opening of the painting, background fog coalesces into a band that moves forward, passes in front of trees, moves into the deep distance, and wafts back to the middle ground; there, in contrast, the mist passes behind the trees at the head of a grove. At the left end of the composition, the band of mist re-expands to a general fog.

The thick mist calls attention to the distant/near oscillation and reminds us of one important function of clouds in poetry: the obscuring of vision and judgement. Song Yu 宋玉 (ca. 290-ca. 223 BCE), an official of the state of Chu 楚, bemoaned the thick clouds that blocked his king's vision: "How the floating clouds drift over everything! See how they suddenly cover up the bright moon!" An early annotation to this line sees floating clouds as a "symbol of the slanderer who darkens the face of truth."24 Du Fu used clouds and mist as literal and metaphorical obstructions to his vision in his long poem Autumn Day in Kui Prefecture (Qiuri Kuifu yonghuai 秋日熟府詠懷). ${ }^{25}$ We cannot be certain if Zhao Lingrang used clouds as a symbol of obfuscating vision and truth. We do know, however, that when later artists wrote that they were painting in Zhao Lingrang's style, they "quoted" his thick bands of mist. ${ }^{26}$

Zhao's misty ending is innovative compared to the conclusion of most handscroll compositions of the eleventh century. Typically, the beginning of a composition at the right invites the viewer to enter and move toward the left. The conclusion, by contrast, is often an emphatic barrier beyond which the viewer cannot easily travel. In some paintings a boat or traveler moves from the left edge to turn the viewer's attention back into the landscape just visited. The last inches of the mid-eleventh-century SummerMountains (Xia shan tu 夏山圖) are a prime example (fig. 5). 
FIGURE 3A. Zhao Lingrang,

Summer Mist along the Lakeshore,

detail of two birds in willows
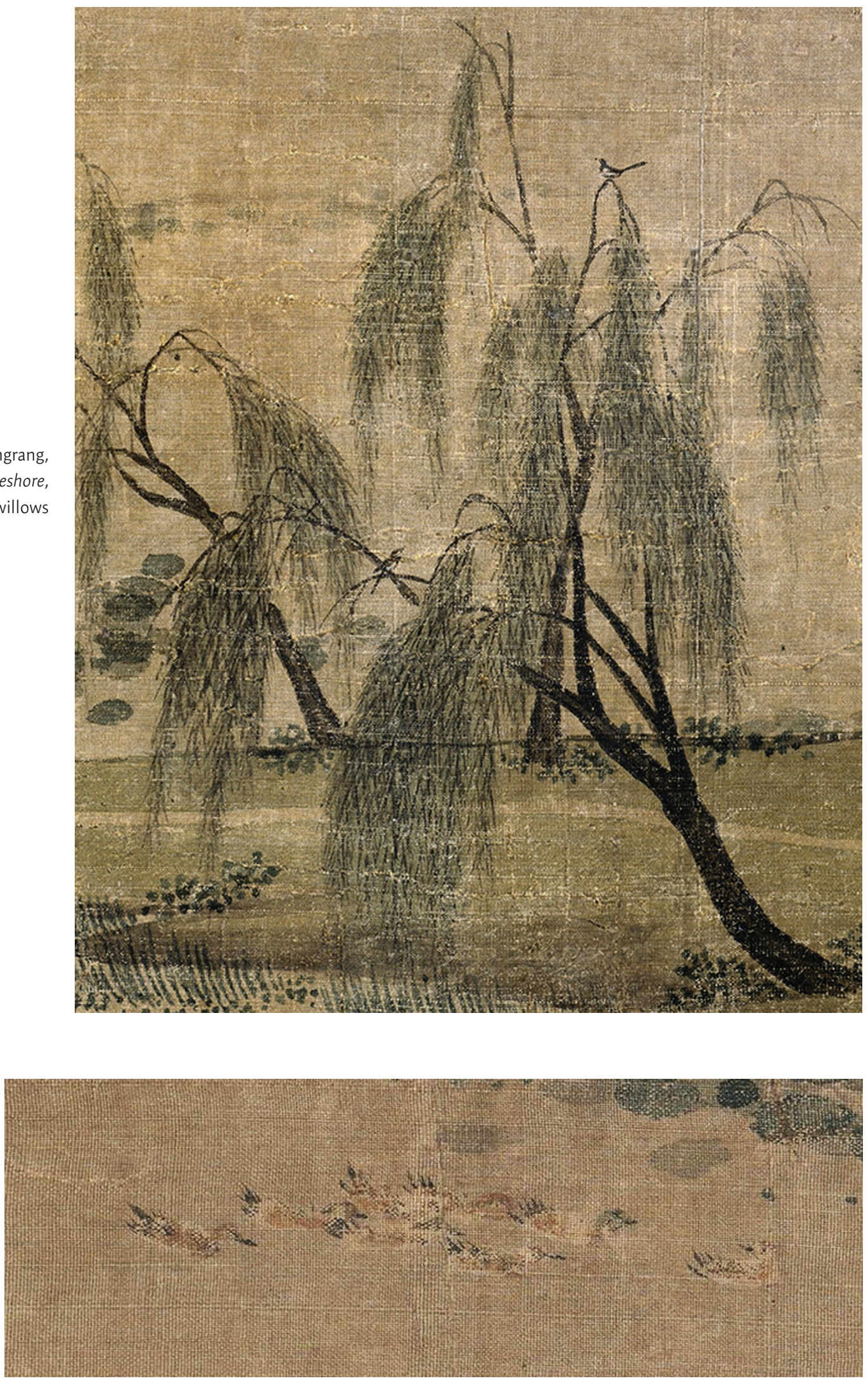

FIGURE 3B. Zhao Lingrang, Summer Mist along the Lakeshore, detail, eight of the numerous ducks on the water 


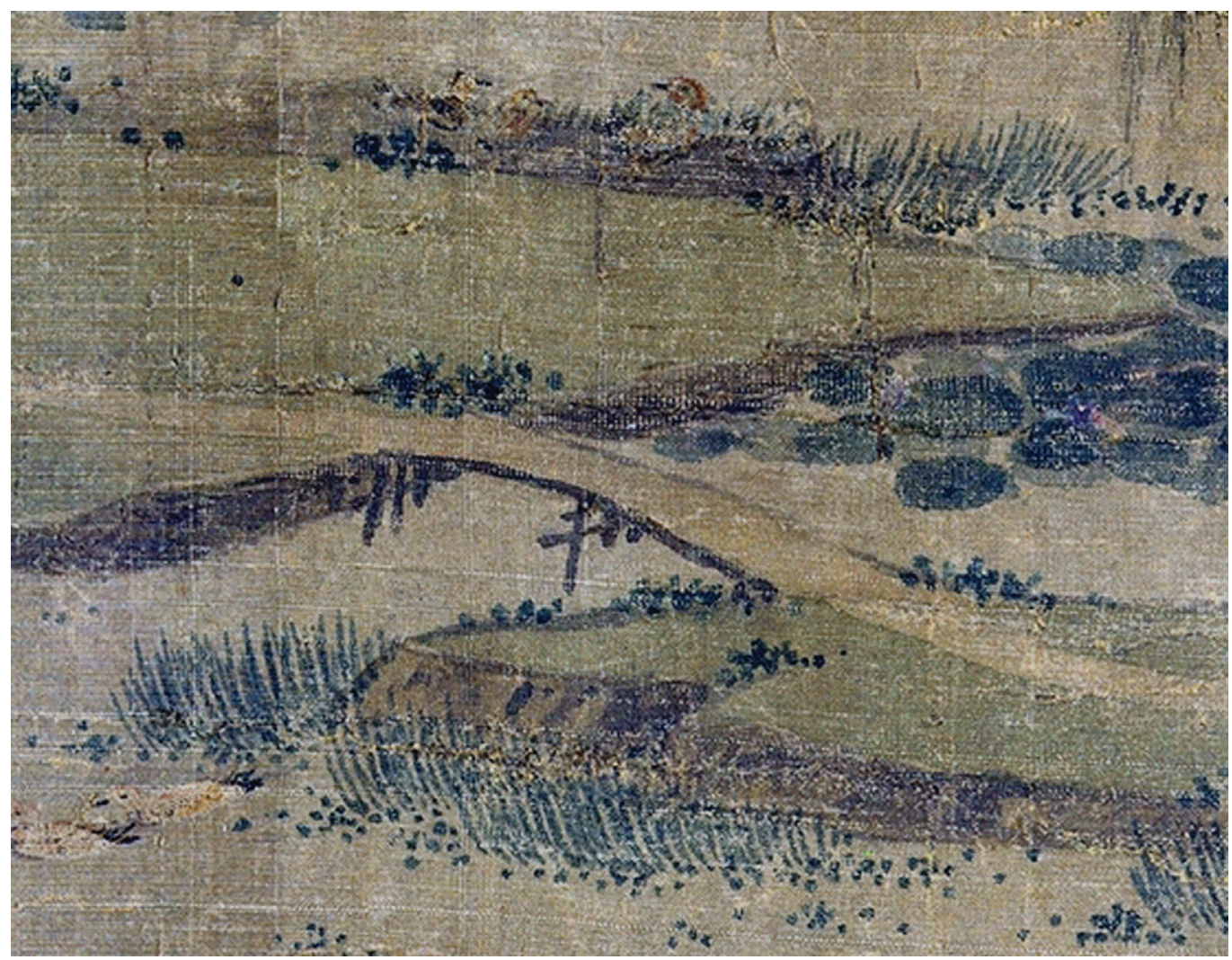

FIGURE 4A. Zhao Lingrang, Summer Mist along the Lakeshore, detail of earth-topped bridge near opening of scroll

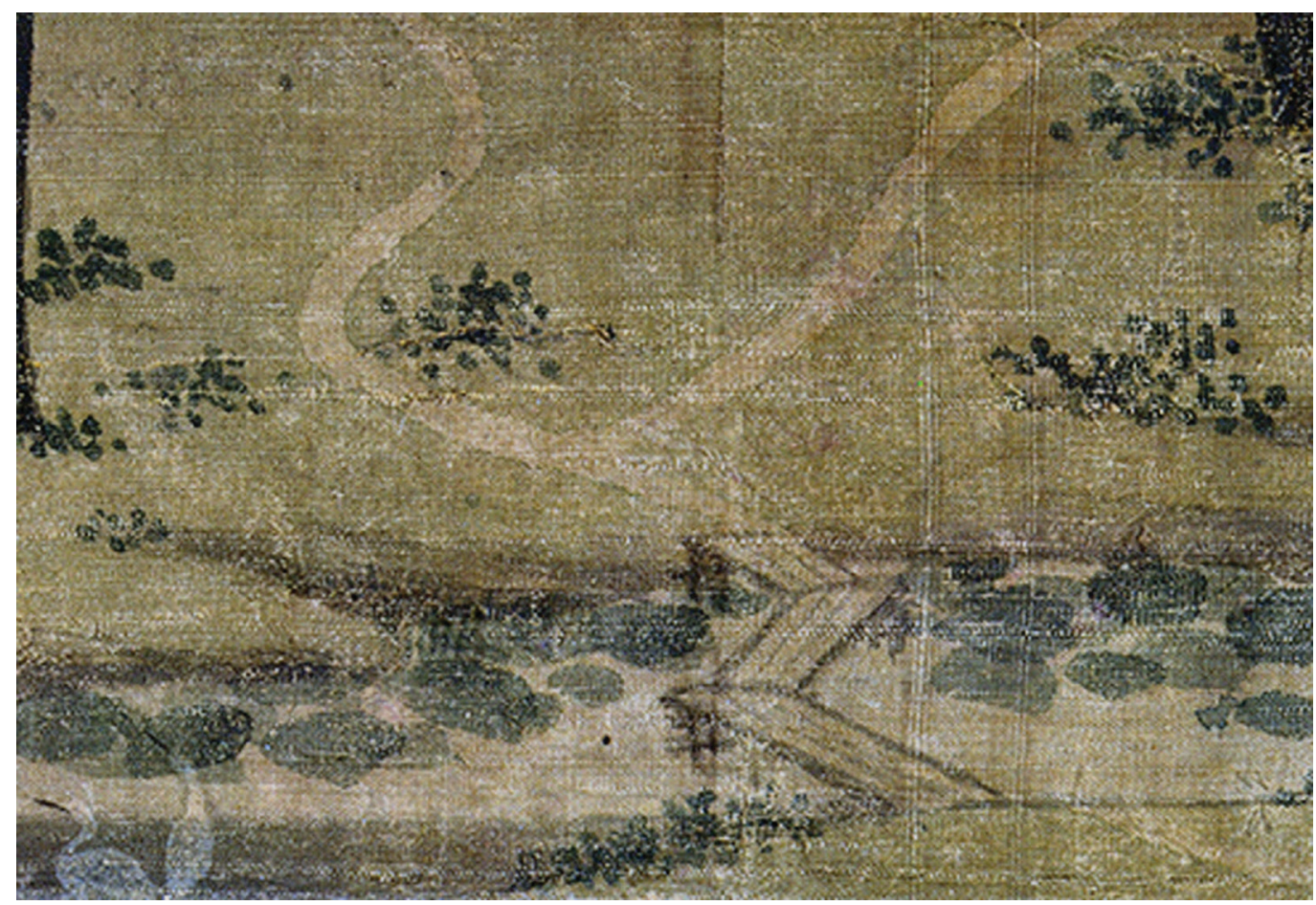

FIGURE 4B. Zhao Lingrang, Summer Mist along the Lakeshore, detail of smaller zigzag plank bridge to left 
At the end of the composition, trees and a cataract discourage further travel to the left. Instead, an itinerant with a shoulder pole is crossing a bridge. Walking to the right, he leads us back to revisit the painting's entertaining details. Zhao Lingrang ended Summer Mist with a vaporous void, which forms a contrast with the solid earthen bank at the opening of his composition. The contrast of opposites and their reconciliation is a desirable feature in Chinese poetry, as is an open-ended closure. But Zhao did not completely abandon the convention of directing the viewer back into the landscape. While four ducks fly to the left, the tree at right in the group of three trees reaches to the right, seemingly pointing us to return to the scene (fig. 6).

Finally, it is important to remember that the level distance (pingyuan 平遠) of Zhao's painting is more than a compositional device. In the poetry of banished officials, living on rivers and lakes (jianghu shang 江湖上) became a euphemism for living in exile; the disgraced official, who had no choice in the matter, rubbed shoulders with the fishermen and woodcutters who lived in remote places, contentedly outside the hierarchy of court culture. The increase in river and lake scenery in the 1080s has been noted by Richard Barnhart, who draws a correlation between exile and paintings of flat, watery vistas. One of the "paintings of exile" that he singles out is Wang Shen's Misty River, Layered Peaks (Yanjiang diezhang tu 煙江疊嶂圖), datable to 1088, more than half of which features heavy mist along the Yangtze River 長江. ${ }^{27}$ The punishment given to Zhao Lingrang's friends who were sent into exile was administrative confinement (anzhi 安置); ironically, perhaps, Zhao and all other imperial clansmen who were potential competitors for the throne endured their own gentle equivalent of administrative confinement, in that they were restricted to the environs of the capital. ${ }^{28}$ When Mi Fu wrote that Zhao Lingrang's "riverbanks with waterfowl have intimations of rivers and lakes," he may have been implying a sympathy with the Yuanyou exiles. ${ }^{29}$ In a similar vein, the official Zhao Mengfu of the Yuan dynasty (1279-1368) wrote that it was remarkable that a young nobleman, living in a peaceful time and amusing himself with brush and ink (that is, not living as a deprived exile), could nonetheless grasp the "flavor of rivers and lakes." 30

FIGURE 5. Qu Ding (attr.; active ca. 1023-ca. 1056), Summer Mountains (detail), ca. 1050. Handscroll, ink and color on silk; image: $45.3 \times 115.2 \mathrm{~cm}$. The Metropolitan Museum of Art, New York, Ex coll.: C.C. Wang Family, Gift of The Dillon Fund, 1973, 1973.120.1

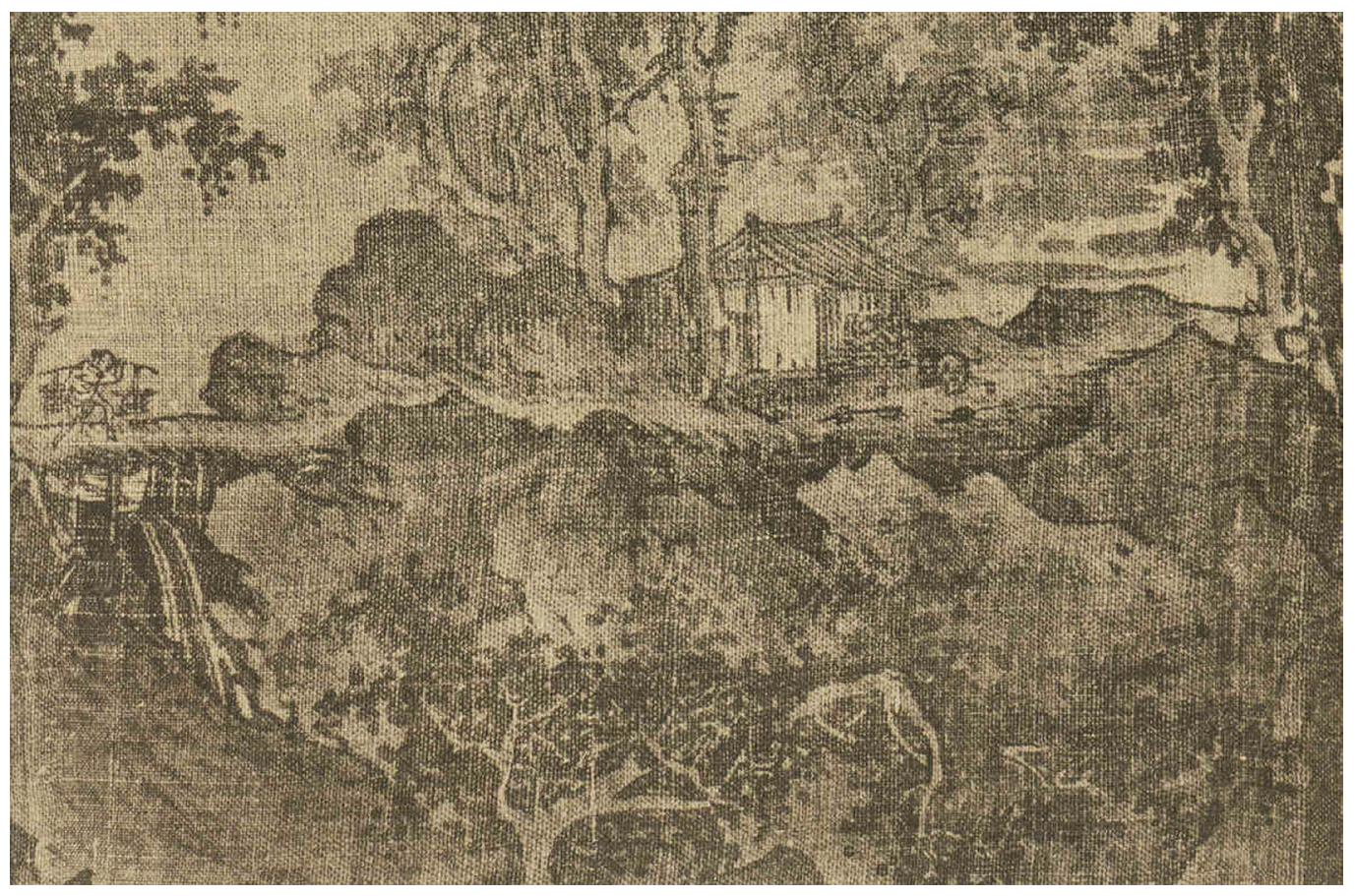




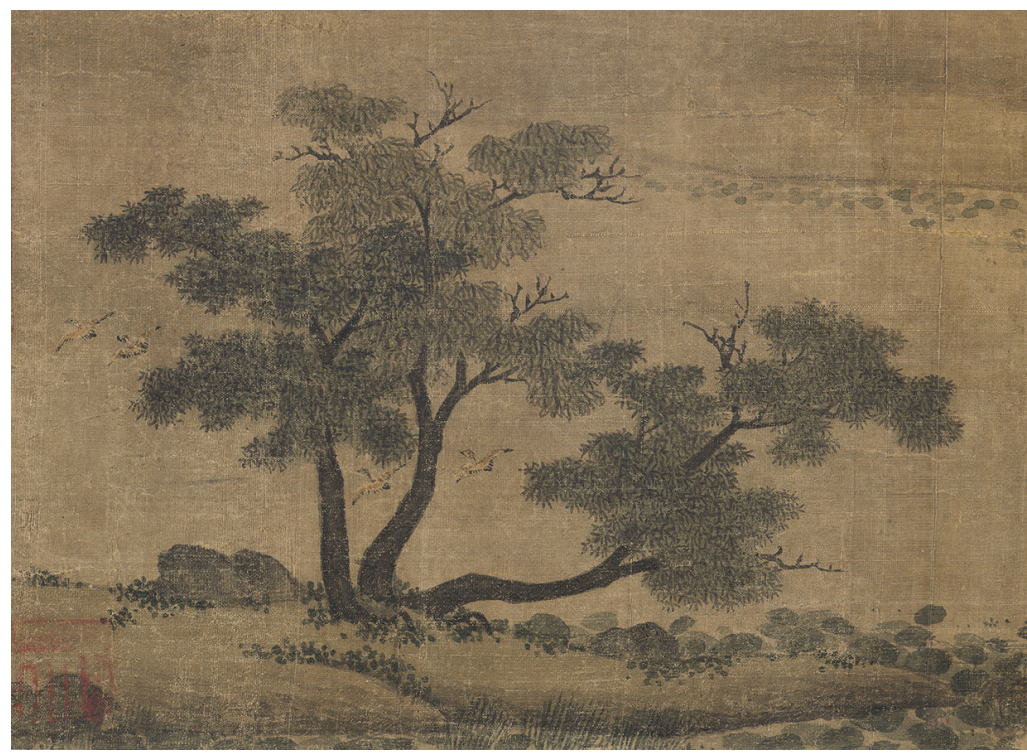

FIGURE 6. Zhao

Lingrang, Summer Mist along the Lakeshore, detail of trees at end of composition, with mix of bare and leafy branches and right tree leaning back into the landscape

\section{Poetic Tropes}

\section{Leafless Branches}

In reproducing poetic forms, painting had its limitations. Visually replicating the orality of rhyme words was challenging, if not impossible, as was the picturing of level and oblique tonal patterns within the five- or seven-character lines. By comparison, painting poetic metaphors was easy. In Zhao Lingrang's erudite circle of friends, what did his leafless branches on otherwise flourishing trees suggest? Bare branches stick out of almost all of the trees. We should resist the impulse to read them as indicative of autumn. In poetry, a better guide to understanding the absence of leaves is a longstanding metaphor for talent being neglected.

The initial meaning of the poetic binome "falling leaves" (luo ye 落葉) arose from annotations to "The Ladies of the Xiang" (Xiang furen 湘夫人), one of the Nine Songs (Viuge 九歌) attributed to the poet and official Qu Yuan 屈原 (ca. 340-278 BCE) in the early anthology Songs of the South (Chu ci 楚辭). The line on leaves falling into the waves of Dongting Lake (Dongting bo xi muye xia 洞庭波兮木葉下) was interpreted by the poet and annotator Wang Yi 王逸 (ca. 89-ca. 158) to mean that people were anxious, and that worthy men had been injured. The metaphor was embellished over the centuries; in the early eighth century, annotators added that falling leaves were a metaphor for petty men managing affairs, and therefore worthy men being cast aside. ${ }^{31}$

Wang Wei used the metaphor of falling leaves to great effect in a poem written during the An Lushan rebellion (755-63). In the chaos of the fighting, Wang was captured by rebels and held at the Bodhi Monastery 菩提寺. In later tellings, his friend Pei Di 裴迪 (b. ca. 714) managed to visit him at the monastery, and breathlessly related recent events: the emperor and court had fled the capital; An Lushan 安祿山 (ca. 703-757) and his troops held a banquet in the palace; they commanded the Pear Garden musicians (the imperial orchestra personally trained by Emperor Minghuang 明皇, r. 713-56) to perform. The musicians began to weep; one musician threw down his instrument and turned in the direction that the emperor had fled. $\mathrm{He}$ was dismembered on the spot as an example to the others present. Hearing this news, Wang Wei is said to have composed and recited the following poem to Pei Di: 
From thousands of aggrieved households wilderness smoke rises, When will the hundred officials be presented to court again?

Autumn scholar tree leaves fall within the empty palace;

Beside Frozen Jade Pond they played pipes and strings. ${ }^{32}$

萬戶傷心生野煙, 百僚何日更朝天。秋槐葉落空宮裏, 凝碧池頭奏管弦。

The third line alludes to leaves falling in the vacated palace, empty of the imperial court but not of the would-be emperor An Lushan. The leaves that fell were not just any leaves, but were from the scholar tree (huai 槐, also called Sophora tree) that puts forth fragrant blossoms in late summer, and that was much admired by the elite. Thus, scholar-tree leaves falling in the palace signaled Wang Wei's anguish at the death of talented men. A Song-dynasty scholar claimed that Wang would have been convicted of collaborating with the rebels except for this poem. ${ }^{33}$ The falling leaves signaled his grief.

In Zhao Lingrang's painting, the trees are not completely leafless, nor are any of the leaves in the midst of falling. Leaves had fallen: an emperor died an early death, and friends' careers had been thwarted. Now, however, the trees are putting forth greenery; the new emperor had declared an amnesty that would bring friends back to the capital. It is entirely possible that the renewed trees were read as an adroit assertion of new beginnings, and also could be understood as nature's positive response to a charismatic leader.

\section{Stream with Rocks}

At the center of Summer Mist, Zhao painted a stream flowing over rocks (fig. 7). Not every painter intended poetic meanings in a stream tumbling over rocks, but Zhao Lingrang was not an ordinary artist. He was a scholar knowledgeable about poetry and aware of current events. Zhao's stream and rocks reference two literary phrases that were appearing in the poetry of his contemporaries. ${ }^{34}$

The first is the compound chan yuan 潺湲, which is particularly useful for its dual meaning. The primary definition is water flowing over rocks, both in limited volume (like a brook) or in a great gush. From that natural phenomenon emerged a second lexical meaning of copious tears streaming down cheeks. The early poetry anthology Songs of the South contains lines that use both meanings separately. Tears stream down the cheeks of the exiled loyal official Qu Yuan;

FIGURE 7. Zhao

Lingrang, Summer

Mist along the Lakeshore, detail of stream with rocks

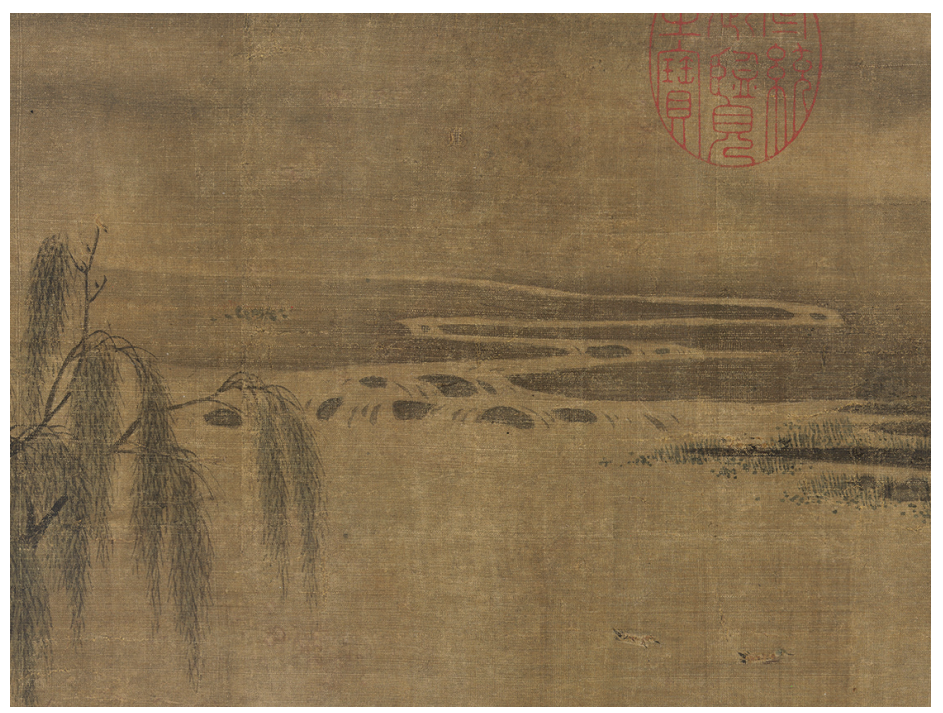


elsewhere in the anthology chan yuan describes water flowing through gullies. ${ }^{35}$ After the devastating An Lushan rebellion, Du Fu wrote of guests at a banquet weeping in sorrow (chan yuan) when they heard the music of the formerly glorious Kaiyuan 開元 reign (713-41), as they recalled the musicians of the Pear Garden and the events at An Lushan's banquet. ${ }^{36}$

Huang Tingjian used "stream flowing/tears falling" in ten of his poems, but by far the most significant for landscape painting was his concurrent evocation of both meanings in "Wind in the Pines Hall" (Songfeng ge 松風閣), datable to 1102. In the poem, which he sent to Zhang Lei, Huang mourned their recently deceased mentor Su Shi, writing, "A dry spring, parched rocks, again have water flowing. ${ }^{177}$ Zhang Lei could not have missed the reference to grief. Artists aware of the dual meaning of chan yuan could render a stream with rocks and simultaneously refer to the secondary meaning of tears and sorrow, as Zhao Lingrang may have done in Summer Mist.

If the first reference suggested by the stream with rocks is both natural and mournful, the second reference is hopeful. Because he painted eight large stones, Zhao Lingrang may have been alluding to the eight-formation diagram that the military strategist Zhuge Liang 諸葛亮 (181-234) was said to have designed.

In the biography of Zhuge Liang, the phrase "eight-formation diagram" (bazhen tu 八陣圖) appears without elaboration. ${ }^{38} \mathrm{~A}$ century and a half later, the general Huan Wen 桓溫 (312-373) of the Eastern Jin dynasty (317-420) was travelling up the Yangtze River and saw approximately sixty boulders in shallows above the Three Gorges. The evenly spaced, round rocks begged for an explanation of intelligent design. Thinking of Zhuge Liang's biography, Huan Wen decided that this must be the eight-formation diagram. Huan's official biography gives this account:

Zhuge Liang had made the eight-formation diagram on the sands at Fish Return [Yufu 魚復 in present-day Fengjie, Chongqing]. He arrayed stones in eight rows that were two zhang 丈 [twenty feet] apart. When Huan Wen saw them, he exclaimed, "This is like the force of the snake on Chang Mountain 常山.” Neither civil nor military officials can fathom it. ${ }^{39}$

Huan Wen likened the rocks to the Chang Mountain Snake, which was the name of a troop formation that moved as fluidly as a snake to encircle an enemy. "If you strike its head, its tail comes to its aid," and vice versa. "If you strike its middle, both head and tail come to its aid." 40 Visible only when the river was low, the boulders were probably a moraine left behind by a receding glacier. To Huan Wen, they were none other than Zhuge's eight-formation diagram.

If this metaphoric reading of Zhao Lingrang's little stream with rocks seems improbable, it is well to remember that, because of nearly constant border conflicts, military strategy was a topic of absorbing interest among Northern Song scholars. During the eleventh century, military texts were circulating widely for the first time due both to the new technology of printing and to the government's recognition that peasants did not rebel because of reading books. ${ }^{41} \mathrm{Schol}$ ars read about the eight-formation diagram in military treatises and in Tang-dynasty poetry.

The poet Du Fu, who lived for several years in the neighborhood of the eye-catching rock formation, cited them as a feature of Kuizhou 颜州: “Battle formation in sand along the north bank, Market-end near the inlet's west peak." 42 For Du Fu, the eight-formation diagram was a mnemonic for Zhuge Liang's unusual life. When the Han dynasty (206 BCE-220 CE) was collapsing, Zhuge Liang was determined not to get involved, but after Liu Bei 劉備 (161-223), the powerful general from the state of Shu 蜀, personally called on him, Zhuge was persuaded to join the cause of reuniting the empire. ${ }^{43}$ In a poem occasioned by a visit to a temple commemorating Zhuge Liang, Du Fu longs for a ruler who will recruit and collaborate with talented men: 
"Ruler and subject then worked together, a worthy man and a sage, living at the same time."44 In a quatrain titled "Eight-Formation Diagram" (Bazhen tu 八陣圖), Du Fu again goes beyond notions of troop dispositions to declare Zhuge Liang's heroic efforts:

His deeds covered a kingdom split in three,

His fame completed the eight-formation diagram;

The River flows, the rocks do not turn,

Remnant bitterness at failure to swallow Wu. ${ }^{45}$

Du Fu's quatrain prompted Su Shi to write an interpretation that is framed as a dream encounter with the poet, but that clearly refers to struggles of his own time:

I often meet people in dreams. For example, Du Fu once said to me, "Most people misunderstand my poem Eight-Formation Diagram. The poem says, 'The River flows, the rocks do not turn/ Remnant bitterness at failure to swallow [the state of] Wu 吳.' Everyone assumes that Liu Bei and Zhuge Liang, like Guan Yu 關羽, wanted to take revenge, and that the poem expresses regret at not being able to destroy Wu. Not so! My meaning was that Wu and Shu were countries as close as teeth and lips that should not plot against each other. Jin 晉 was able to subdue Shu because Shu was thinking about capturing Wu. This [misunderstanding] is really annoying."

Su Shi continues, "This experience was truly profound. Du Fu has been dead for almost four hundred years, but because I cannot forget the poems' minutiae, I naturally distinguish his meaning. This truly is the 'vulgar habit' of a bookish student." 46

Su Shi's dream encounter with Du Fu speaks to military and border issues of his own time. According to Su Shi, what Du Fu really meant was that Liu Bei and Zhuge compromised their own survival by fixating on seizing the territory of Wu. Su Shi moved the conversation from warfare to the importance of conciliation: it's better to form alliances with friendly neighbors than to covet their territory. ${ }^{47}$

Su Shi and his brother Su Zhe 蘇嘾 (1039-1112) climbed a mountain across the Yangtze River to look down on the eight-formation diagram. In Su Shi's hyperbolic description, the formation was truly colossal:

Zhuge Liang created the eight-formation diagram on flat sands at Fish Return. Rocks were placed in eight ranks that are spaced twenty feet apart. Huan Wen, on an expedition to put down Qiao Zong's 譙縱 rebellion, saw them and said, "These have the power of the Chang Mountain Snake. Neither civil nor military officials could fathom it." I once passed them. From on top of the mountain looking down, [they stretched] more than a thousand feet, altogether eight rows with their ranks marked by sixty-four bundles of grass. All bundles were perfectly round without protrusions or indentations; like shadows of canopies at noon. Even looking closely, they were like endless indistinguishable pebbles. Amazing. ${ }^{48}$

Others gave more modest dimensions, but whatever its scale, the rock formation stimulated the imagination of military and political tacticians as well as authors of poetry and novels. ${ }^{49} \mathrm{Su}$ Zhe's “Eight-Formation Diagram at Low Water" (Bazhen ji zai Kuizhou 八陣磧在熟州) opens with the observation that when the river is high, the rocks are submerged: "At flood the river beats upon the eight-formation diagram,/the river drops, formation as before." 50 
In 1082 Su Shi wrote two odes on the Red Cliff 赤壁, the first in the seventh month, the second in the tenth month. Su Shi was in exile, confined to the hamlet of Huangzhou 黃州 on the Yangtze River, not far from the Red Cliff. ${ }^{51}$ There a sensational naval battle had taken place in 208. Cao Cao 曹操 (ca. 155-220) was defeated by a smaller force led by Zhuge Liang and Zhou Yu 周瑜 (175-210), who sent burning ships into Cao's massive fleet.

In Latter Ode on the Red Cliff (Hou Chibi fu 後赤壁賦), Su Shi referred to Zhuge Liang's eightformation diagram with the phrase "water drops, rocks revealed" (shui luo shi chu 水落石出). The reference is plausible, as Su was writing in the aftermath of a Song dynasty military defeat. In 1081 and 1082, Emperor Shenzong ordered incursions into Tangut territory, determined to take territory that previously had been part of the Tang state. Bad decisions and poor preparations (his forces neglected to bring siege equipment) led to the loss of tens of thousands of leaders and soldiers. Wanting to reverse that expensive and humiliating defeat, Song armies made another attempt in the fall of 1082. Against sage advice, Shenzong put a brash but inexperienced official in charge. In the ninth month of 1082, the Song defeat at Yongle Cheng 永樂城 was worse than before. The combined losses were estimated at as many as two hundred thousand troops. ${ }^{52}$ In the context of these events of 1082, it is reasonable to infer a reference to the eight-formation diagram and the need for wiser military strategy. ${ }^{53}$

The lengthy description above serves to explain that the "eight-formation diagram" had become part of the conversation among the educated elite of the Northern Song. Was it possible for an artist to capture the idea symbolically with eight or nine boulders, as Zhao Lingrang may have done in 1100? About two decades later, Qiao Zhongchang 喬仲常 (active early 12th century) illustrated Su Shi's Latter Ode on the Red Cliff. His depiction of Su's line on rocks emerging has Su Shi as a monumental figure seated between two friends on a bank above rocks jutting out of the river (fig. 8).

Su Shi's interest in rocks emerging from water also appears in connection with Wang Wei. As noted above, Su observed that Wang Wei's poems contain paintings and his paintings have poetry. Su wrote the famous formula in a colophon for the painting Mist and Rain at Lantian (Shu Moji Lantian yanyu tu 書摩詰藍天煙雨圖) by Wang Wei, after which Su transcribed a quatrain that he attributed to Wang:

White rocks emerge from Jing Stream, red leaves are few at Jade River.

On the mountain path originally without rain, only kingfisher green dampens people's

clothes.

荊徯白石出, 玉川紅葉稀。山路元無雨, 空翠濕人衣

Su Shi then acknowledged that others said the poem was not by Wang Wei, but that an enthusiast had used it to supplement Wang's legacy. ${ }^{54}$ Was Su hinting that he was the author? The poem resembles Wang Wei's serene syntax, but that did not persuade the editors of Complete Tang Poems (Quan Tangshi 全唐詩; 1705) to include it. In the context of viewing a painting, the quatrain is amusing: it seems to imply that, although no rain is falling, clothes are still getting wet from bright green pigment. Whoever the author may have been, Su was more than willing to link Wang Wei to rocks jutting out of water, with the motif's implied evocation of Zhuge Liang.

In poetic discourse from the fourth to the eleventh century, the eight-formation diagram could refer to the actual boulders near Kuizhou, to the military strategist Zhuge Liang, to the need for wise military strategy, and, perhaps most relevant for officials like Su Shi, to a ruler seeking 
FIGURE 8. Qiao Zhongchang (active early 12 th century), Latter Ode on the Red Cliff (detail), ca. 1120. Handscroll, ink on paper; image and colophon:

$30.5 \times 629.3 \mathrm{~cm}$

Nelson-Atkins Museum of Art, Kansas City, Purchase: Nelson Gallery Foundation, F80-5

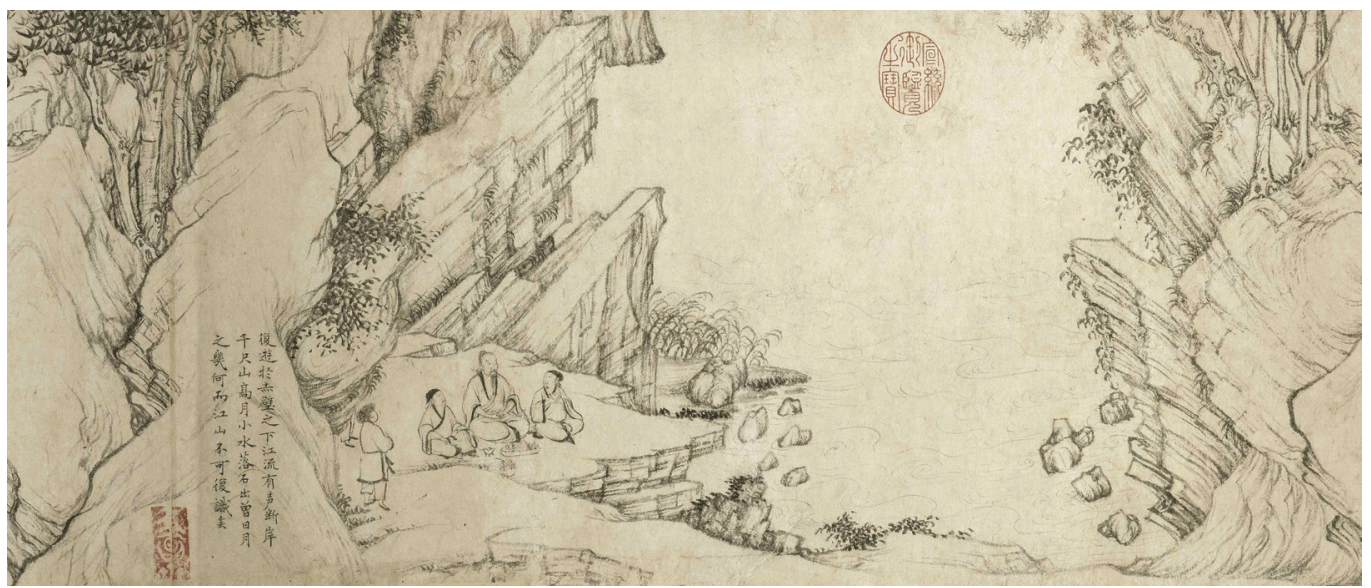

out and collaborating with a talented man. Through an image of rocks emerging from water, the reference to Zhuge Liang's eight-formation diagram was easily transposed into visual language.

\section{Conclusion}

The late eleventh-century shift from monumental landscape painting to intimate small views was accompanied by an expectation-promoted by Su Shi and others-that painting could be a vehicle for individual expression like that found in poetry. As scholars introduced metaphors into their paintings, connoisseurs realized that their knowledge of poetry and history was vital to understanding the visual content. ${ }^{55}$

Summer Mist along the Lakeshore is Zhao Lingrang's most obvious contribution to poetizing painting. Following his poetic training, Zhao appears to have structured Summer Mist after a regulated quatrain. If Zhao Lingrang was using Wang Wei's brush ideas, as Dong Qichang claimed, we may conclude that he was taking a poet's approach. Analyzed from the perspective of the events of 1100-the untimely death of a young emperor, imperial mourning, installation of Zhao's former pupil as the new emperor, and a general amnesty-it is reasonable to conclude that Zhao Lingrang was painting common literary metaphors of grief and hope. Was he anticipating that the new sovereign would wisely seek out talented officials? In Chinese painting's literary turn, Zhao Lingrang's handscroll is much more than a peaceful summer landscape. It is possible that Summer Mist was Zhao's effort to paint a poem in a synesthetic melding of form and metaphors that his knowledgeable friends would have recognized and appreciated.

The major academic interest of Alfreda Murck, PhD (Princeton University), 1995, has been how educated men of dynastic China communicated joys, sorrows, and complaints through the depiction of poetic metaphors. She has authored various articles on Chinese visual culture and the book Poetry and Painting in Song China: The Subtle Art of Dissent (Harvard University Asia Center). Working in Beijing for seventeen years, she collected twentieth-century artifacts and curated the exhibition Mao's Golden Mangoes and the Cultural Revolution (Museum Rietberg, Zurich).E-mail: alfreda.murck@gmail.com

\section{Notes}

I extend my thanks to Martin Powers for including me in this project and to Nancy Berliner, Curator at the Museum of Fine Arts, Boston, who kindly arranged for me to view the Zhao Lingrang scroll. Friends, colleagues, and two anonymous 
readers have improved this essay with thoughtful suggestions and queries. Particular thanks go to Shi-yee Liu and Joseph Scheier-Dolberg of the Metropolitan Museum of Art's Asian Art department, who generously shared information, manuscripts, and thoughts on Zhao Lingrang's art. I give special thanks to Julia Murray, Andrew Plaks, Ellen Soulliere, and Nancy Norton Tomasko for their insights. Remaining errors and infelicities are my responsibility.

1 Su Shi, Shu Moji Lantian yanyu tu 書摩詰藍田烟雨圖 (Inscribing Wang Wei's Mist and Rain at Lantian), in Su Shi wenji 蘇軾文集 (Su Shi's collected prose), ed. Kong Fanli (Beijing: Zhonghua shuju, 1986), juan 70, 2209.

2 Zhao Lingrang was a fifth-generation descendent of the emperor Song Taizu 宋太祖 (r. 960-76). See John. W. Chaffee, Branches of Heaven: A History of the Imperial Clan of Sung China (Cambridge, MA: Harvard University Asia Center, 1999), 265, 270.

3 Biyi quan fang Youcheng 筆意全倣右丞. From Dong Qichang's first colophon, dated 1596, on Summer Mist along the Lakeshore, in Kohara Hironobu and Fu Shen, Tō Kishō no shoga 董其昌之書法 (The calligraphy of Dong Qichang) (Tokyo: Nigensha, 1981), 78, 255.

4 Wang Wei, "Ouran zuo, liu shou zhi liu" 偶然作, 六首之六 (Sixth of six occasional poems), in Quan Tang shi 全唐詩 (Complete Tang poetry), comp. Cao Yin (1658-1717) et al. (Beijing: Zhonghua, 1960), juan 125, 1254.

5 Robert E. Harrist, Jr., Painting and Private Life in Eleventh-Century China: Mountain Villa by Li Gonglin (Princeton, NJ: Princeton University Press, 1998), 69-70.

6 Preface (dated 1123), Xuanhe huapu 宣和畫譜 (Xuanhe catalogue of paintings), in Huashi congshu 畫史叢書 (1962; reprint, Taipei: Wenshizhe, 1974), juan 10, 475-78.

7 Tung Wu, Masterpieces of Chinese Painting from the Museum of Fine Arts, Boston: Tang through Yuan Dynasties (Boston: Museum of Fine Arts, 1996), 22-23. For the siyin half-seals, see Huiping Pang, "The Multiple Siyin Half Seals: Reconsidering the Dianli jicha si (1373-1384) Argument," Journal of the American Oriental Society 134.3 (2014): 361-83.

8 Dong's earliest two inscriptions are dated 1596; the second-to-last is dated 1629 . His last inscription, on the brocade separating the painting and colophons, was written at the invitation of the new owner, Wang Shimin. Dong's seven colophons are reproduced and transcribed in Kohara and Fu, Tō Kishō no shoga, 78, $84,140,188,189,255,257,263$, and 267-68.

9 The painting bears collection seals of the Qianlong 乾隆 (r. 1736-95), Jiaqing 嘉慶 (r. 1796-1820), and Xuantong 宣統 (r. 1909-11) emperors. For a highresolution image of the entire painting and colophons, see the University of Chicago website "East Asian scroll paintings," https://scrolls.uchicago.edu/ (last accessed March 3, 2019).
10 Chen Rentao, comp., Gugong yiyi shuhua mu jiaozhu 故宮已佚書畫目校注 (Annotated catalogue of painting and calligraphy lost from the Palace) (Hong Kong: Tongying gongsi, 1956), 4b.

11 Robert J. Maeda, "The Chao Ta-nien Tradition," Ars Orientalis 8 (1970): 243-53. Surveying Chinese paintings of water, Maeda further credits Zhao with indicating water without any brushwork by simply painting lily pads at the water's edge. Robert J. Maeda, "The 'Water' Theme in Chinese Painting," Artibus Asiae 33.4 (1971): 24.

12 Deng Chun, Hua ji 畫繼 (Painting continued), juan 2, in Huashi congshu, 1:275.

13 Cai Tao (11th-12th century), Tiewei shan congtan 鐵圍山叢談 (Collection of talks from the Iron mountains surrounding this mundane world), juan 1 . https://zh.wikisource.org/wiki/鐵圍山叢談 (last accessed February 20, 2019).

14 Chen Gaohua, Song Liao Jin huajia shiliao 宋遼金 畫家史料 (Historical materials on painters of the Song, Liao, and Jin eras) (Beijing: Wenwu chubanshe, 1984), 408-22, includes most of the poems and comments on Zhao and his painting. My thanks to Joseph Scheier-Dolberg for sharing with me his unpublished manuscript "Summer Mist along the Desolate Lakeshore: A Reconsideration of Zhao Lingrang," in which he documents the close connections between Zhao Lingrang and Su Shi's circle, challenging the view that Zhao's landscapes are polite, refined pictures with little content.

15 Huang Tingjian, "Ti zongshi Danian, Yongnian hua" 題宗室大年, 永年畫 (Inscribing paintings by imperial clansmen [Zhao] Danian and Yongnian), in Chen Gaohua, Song Liao Jin, 411.

16 Dong Qichang wrote this in his first colophon on Summer Mist; see Kohara and Fu, Tō Kishō no shoga, 78, 255. Martin J. Powers has identified art-historical citation as an important factor in the Northern Song shift from illusionistic to individually expressive painting: artists who rejected court standards combined, in one composition, stylistic features from different periods. Martin J. Powers, "The Temporal Logic of Citation in Chinese Painting," Art History (2014): 745-63.

17 Patricia Ebrey, Emperor Huizong (Cambridge, MA: Harvard University Press, 2014), 54-55. Zhezong died on the Yimao 乙卯 day of the first month (February 23, 1100, in the Western calendar); Huizong was installed on the same day. Song shi 宋史 (History of Song) (Beijing: Zhonghua shuju, 1977), juan 19, 357. 
18 For detailed accounts of the policies, their consequences, and the resulting political struggles, see Paul Jakov Smith, "Shen-tsung's Reign and the New Policies of Wang An-shih, 1067-1085," and Ari Daniel Levine, "Che-tsung's Reign (1085-1100) and the Age of Faction," in Cambridge History of China, vol. 5, part one, The Sung Dynasty and Its Precursors, 907-1279 (Cambridge: Cambridge University Press, 2009), 347-483, 484-555.

19 Some Japanese painters working in the Chinese literati style (J. bunjinga 文人畫) adapted this compositional formula for pairs of six-fold screens and sliding-door panels, such as The Four Accomplishments by Kano Motonobu 狩野元信 (1477-1559) in the Metropolitan Museum. See Alfreda Murck, Poetry and Painting in Song China: The Subtle Art of Dissent (Cambridge, MA: Harvard University Asia Center, 2000), 210-25.

20 An essential feature of Chinese poetry, complementary opposites or parallelism (dui ou 對偶) is a rhetorical device that opposes within a couplet similar and antithetical categories (lei 類) such as light/dark, few/many, high/low, motion/stillness, rising/falling, dense/sparse, sun/shade, north/south, and contrasting colors, weather, and time, to name a few.

21 The image recalls Wang Wei's line "In the tall willows, the chirping of early orioles" (gaoliu zaoying $t i$ 高柳早鶯啼), from "Visiting with Monk Xuan"; see Marsha Wagner, trans., Wang Wei (Boston: Twayne, 1981), 126.

22 Although Zhao Lingrang was painting an urban scene, the absence of people resonates with Wang Wei's famous couplet on walking in a seemingly deserted mountain and yet hearing echoing voices. Wang Wei, “Lu zhai” 鹿柴 (Deer park), in Quan Tang shi, juan 128, 1300.

23 Other paintings by or attributed to Zhao Lingrang that feature bands of mist are the handscroll River Village in Autumn Dawn (Metropolitan Museum of Art, New York, 1973.121.2); the album leaf River Landscape in Autumn (Yamato Bunkakan, Nara); and the album leaf Orange and Tangerine Groves (mid12th century; National Palace Museum, Taipei). Max Loehr has noted that, if Cottages in a Misty Grove in Autumn, an album leaf in the Cleveland Museum of Art, were not signed by Li Anzhong 李安忠 (active ca. 1100-1140), it surely would be attributed to Zhao Lingrang. Max Loehr, The Great Painters of China (New York: Harper \& Row, 1980), 158.

24 Wang Yi 王逸 (ca. 89-ca. 158), annotations to the "Nine Arguments" (Viu bian 九辯), in Songs of the South, trans. David Hawkes (Boston: Beacon, 1962), 97-98.

25 Du Fu, "Qiuri Kuifu yonghuai fengji Zheng Jian Li Binke yibai yun” 秋日咅府詠懷奉寄鄭監李賓客一百韻 (Autumn day in Kui Prefecture, a song submitted to Supervisor Zheng and Adviser Li, in one hundred rhymes), lines 37-40, in Du shi xiangzhu 杜詩詳註 (The poetry of Du Fu, annotated), ed. Qiu Zhao'ao (Beijing: Zhonghua shuju, 1985), juan 19, 1701. After autumn winds blow away thick mist, the poet realizes that the sophisticated culture of his youth is permanently lost.

26 Shi-yee Liu, “Qian Xuan's Loyalist Revision of Iconic Imagery: Tao Yuanming Returning Home and Wang Xizhi Watching Geese," Metropolitan Museum Journal (forthcoming 2019), argues that after the fall of the Song dynasty to the Mongols, Zhao Lingrang's style and content represented the Song-dynasty capital Kaifeng and former glory days.

27 Richard Barnhart, "Landscape Painting Around 1085," in The Power of Culture: Studies in Chinese Cultural History, ed. Willard J. Peterson, Andrew H. Plaks, and Ying-shih Yü (Hong Kong: Chinese University of Hong Kong Press, 1994), 195-205. See also Murck, Subtle Art of Dissent, 126-51. Wang Shen's Misty River, Layered Peaks is in the Shanghai Museum.

28 In the twelfth century, Deng Chun 鄧椿 (active 12th century) wrote, "Each time [Zhao] made a painting he tried to create some new ideas. But friends would joke, saying to him: 'This must be the result of your having made another trip to the imperial tombs.' This playful remark referred to his not being permitted to travel long distances, no more than five hundred $l i$ from the capital, so all he ever saw was the scenery between Kaifeng and Luoyang." Deng Chun, Hua ji, juan 2, in Huashi congshu, 1:275.

$29 \mathrm{Mi} \mathrm{Fu}$, Huashi 畫史 (Painting history), in Songren hualun (Changsha: Hunan meishu chubanshe, 2000), 160.

30 Zhao Mengfu, colophon on Zhao Lingrang (attr.), River Village in Autumn Dawn, handscroll in the Metropolitan Museum of Art, New York, https://www .metmuseum.org/art/collection/search/39920 ?searchField=All\&amp; sortBy=Relevance\&amp; $\mathrm{ft}=$ Zhao + Lingrang\&amp; offset $=0$ \&amp; $r p p=20 \& a m p$ ;pos=1 (last accessed February 23, 2019).

31 Alfreda Murck, "Public and Private Truths in Chinese Painting: Zhu Da and Fu Baoshi," in Bridges to Heaven: Essays on East Asian Art in Honor of Professor Wen C. Fong (Princeton, N): The Tang Center, Princeton University Press, 2011), 1:155-56.

32 Translation after Wagner, Wang Wei, 50-51. For the Wang Wei quatrain, see "Lei xia sicheng kouhao tongshi Pei Di” 淚下私成口號詠示裴迪 (Amid tears privately composing an oral verse for Pei Di), in Quan Tang shi, juan 128, 1308.

33 Zhang Biaochen (active 1131-62), Shanhu gou shihua 珊瑚鈎詩話 (Coral belthook poetry comments), juan 3, 4b-5a, in Lidai Shihua 歷代詩話 (Talks on poetry chronologically arranged), comp. He Wenhuan (Taipei: Yinwenguan, 1983), 282-83. 
34 In visual terms, Powers sees Zhao Lingrang demonstrating his command of spatial recession with the stream and rocks. Powers, "Temporal Logic," 750-53.

35 Hawkes, Songs of the South, "While down my cheeks the teardrops in streams are falling," 38; "And in a stream the tears ran down and wet the chariot-bar," 93; "Streams and gullies wind in and out, purling prettily," 105. See also Hong Xingzu, comp., Chu ci buzhu 楚辭補注 (The Songs of Chu with supplementary annotations), 1983 ed. (Beijing: Zhonghua shuju, 2002), 62, 185, 203. The compound chan yuan does not occur in the Book of Odes (Shi jing 詩經), the Analects (Lunyu 論語), or other Confucian classics.

36 Du Fu, Autumn Day in Kui Prefecture, line 48, in Du shi xiangzhu, 2513. The eleventh-century enthusiasm for the poem is discussed in Murck, Subtle Art of Dissent, 265-73. See also Stephen Owen, trans. and ed., The Poetry of Du Fu (Boston: Walter de Gruyter Inc., 2016), 19.41.

37 Huang Tingjian, "Wind in the Pines Hall" (Songfeng ge 松風閣: 泉枯石燥復潺湲), translated in Murck, Subtle Art of Dissent, 163-77. The original manuscript in the National Palace Museum, Taipei, shows that Huang was pleased with this poem: he transcribed it in handsome regular script on beautifully embossed paper.

38 San guo zhi 三國志 (History of the Three Kingdoms) (Beijing: Zhonghua shuju, 1975), juan 35, 927.

39 Huan Wen biography, in Jin shu 晉書 (History of Jin) (Beijing: Zhonghua shuju, 1974), juan 98, 2569. Fish Return (Yufu) is an earlier name for White Emperor City, which is near Kuizhou. The plausible location of the boulders was on the northern shore of the Yangtze River, where it bends around a mountain. It was filled in with earth long before the area was inundated by the water behind the Three Gorges Dam.

40 Roger T. Ames, Sun-tzu: The Art of Warfare (New York: Ballantine Books, 1993), 158.

41 Zhang Yu 張預 (1053-after 1124) wrote a commentary on the Art of War (Sunzi bingfa 孫子兵 法) describing the eight-formation diagram and the value of positioning troops to keep adversaries guessing. Ames, Sun-tzu, 302 n. 265.

42 Du Fu, Autumn Day in Kui Prefecture, in Du shi xiangzhu, 2514. Full poem translated in Murck, Subtle Art of Dissent, 265-73; and Owen, Poetry of Du Fu, 19.41.

43 At the end of the Han dynasty, three states-Wei 魏, Shu, and Wu 吳-emerged to compete for the empire. The state of Shu in the west was headed by Liu Bei, who enlisted the bellicose general Guan Yu 關羽 (d. 220, later deified as the God of War) and strategist Zhuge Liang to help him defeat Cao Cao 曹操 (155-220) and his son Cao Pi 曹丕 (187-226) of Wei in the north and the Sun 孫 clan of Wu in the south. In the end, all were defeated. Shu was conquered by Wei in 263, and Wei was usurped by the Jin dynasty (266-420) in 265; the Jin then went on to conquer Wu in 280.

44 Du Fu, "Zhuge Liang's Temple," after Owen, Poetry of Du Fu, 19.27, 169.

45 After Owen, Poetry of Du Fu, 15.13.

46 Su Shi, Dongpo zhilin 東坡志林 (Dongpo's recollections) (Beijing: Zhonghua shuju, 1981), juan 1.

47 Su Shi, Su Zhe 蘇轍 (1039-1112), and Sima Guang sent memorials to the emperor pointing out that the greater threat was from reckless ministers who started wars in order to seize territory and earn personal glory. Smith, "Shen-tsung's Reign," 354, 478.

48 Su Shi, Su Shi wenji 蘇軾文集 (Su Shi's collected prose), ed. Kong Fanli, vol. 5 (Beijing: Zhonghua shuju, 1986), juan 65, 2018.

49 The most famous treatment of the subject in literature was by the fourteenth-century Luo Guanzhong 羅貫中, who, in the eighty-fourth chapter of Romance of the Three Kingdoms (San guo yanyi 三國志演義), imagined the eight-formation diagram as a fantastic maze.

50 Zhang jiang chui bazhen, jiang luo zhen ru gu 漲江吹 八陣, 江落陣如故. Su Zhe, "Bazhen qi zai Kuizhou" 八陣磧在熟州 (Eight-formation diagram in shallow water at Kuizhou), in Su Zhe ji 蘇軩集 (Collected works of Su Zhe) (Beijing: Zhonghua shuju, 1990), juan 1, 6 .

51 Su Shi sent a copy of the first Ode on the Red Cliff (Chibifu 赤壁賦) to friend Fu Yaoshu 傅堯俞 (1024-1091) with a note asking that he not lightly show it to others-that only one or two people should see it. The terms of Su Shi's exile forbade him from leaving Huangzhou or commenting on government affairs. Even boating on the river was a violation. See the colophon following Su's transcription of the first Ode on the Red Cliff in National Palace Museum, Grand View: Special Exhibition of Northern Sung Painting and Calligraphy, exh. cat. (Taipei: National Palace Museum, 2006), 348-49.

52 Smith, "Shen-tsung's Reign," 472-78.

53 For a full translation of the Latter Ode on the Red Cliff, see Ronald Egan, Word, Image, and Deed in the Life of Su Shi (Cambridge, MA: Harvard University, Council on East Asian Studies, 1994), 245-49. "Water drops, rocks revealed" later became a set phrase meaning "truth will be revealed."

54 Su Shi, Shu Moji Lantian yanyu tu, in Su Shi wenji, juan 70, 2209.

55 For a landscape painting by Song Di, Su Shi wrote, "I know you have a subtle concept; meticulously I will search for it." Su Shi, Su Shi shiji 蘇軾詩集 (Poetry of Su Shi) (Beijing: Zhonghua shuju, 1982), juan 17, 900-901; Murck, Subtle Art of Dissent, 67-68. 